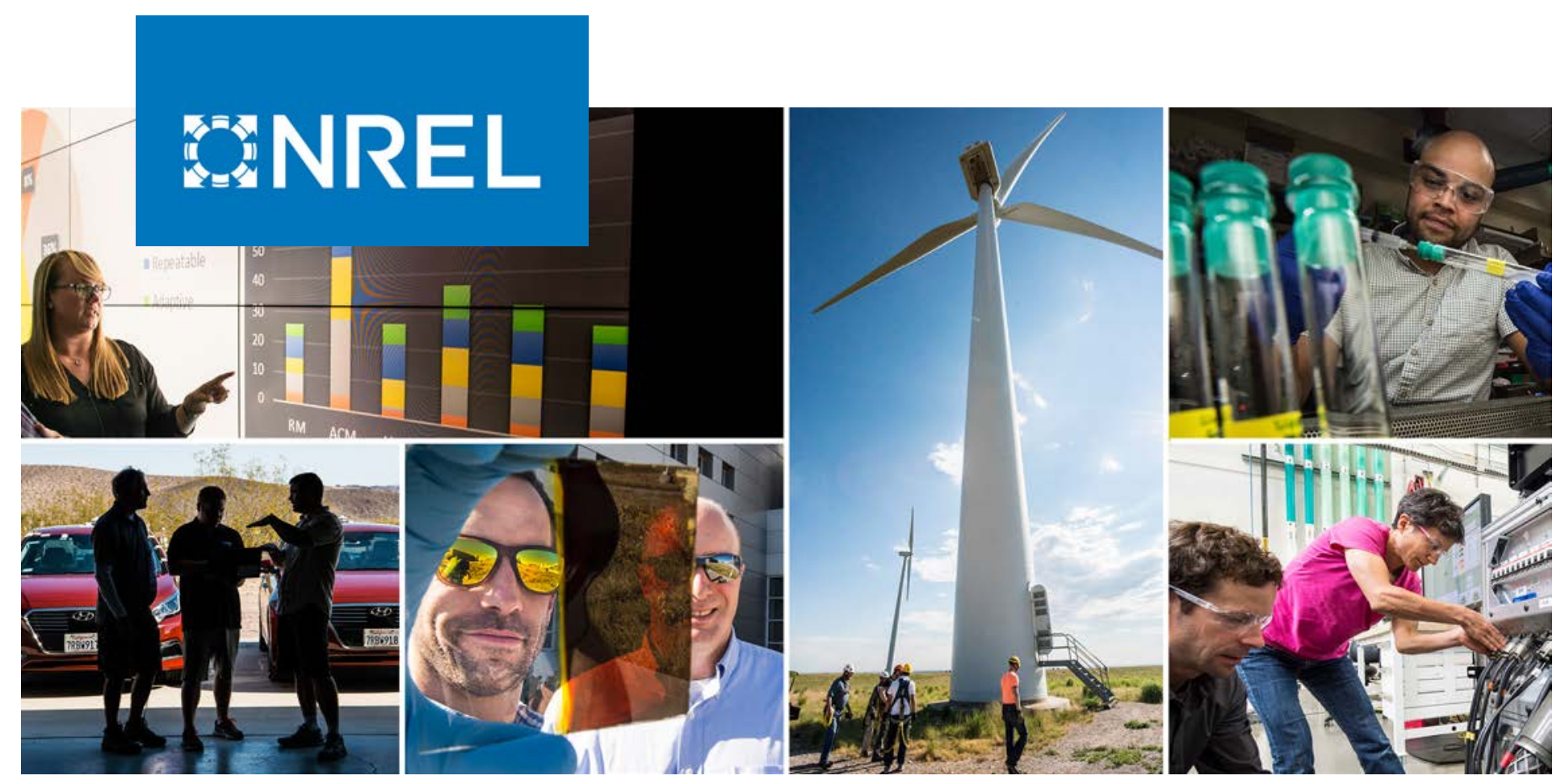

\title{
Analysis of Planar-Cavity Receiver Reactor for Solar Thermochemical Dry-Reforming
}

\section{Preprint}

Jeffrey Gifford ${ }^{1}$, Patrick Davenport ${ }^{1}$, Zhiwen $\mathrm{Ma}^{1}$, Janna Martinek ${ }^{1}$, Craig Turchi ${ }^{1}$ and Jeffrey G. Weissman ${ }^{2}$

1 National Renewable Energy Laboratory

2 Precision Combustion, Inc.

Presented at the ASME 2019 International Mechanical Engineering Congress and Exposition

Salt Lake City, Utah

November 11-14, 2019

NREL is a national laboratory of the U.S. Department of Energy

Office of Energy Efficiency \& Renewable Energy

Operated by the Alliance for Sustainable Energy, LLC

This report is available at no cost from the National Renewable Energy Laboratory (NREL) at www.nrel.gov/publications.
Conference Paper

NREL/CP-5500-73726

August 2019 


\section{GNREL}

\section{Analysis of Planar-Cavity Receiver Reactor for Solar Thermochemical Dry-Reforming}

\section{Preprint}

Jeffrey Gifford ${ }^{1}$, Patrick Davenport ${ }^{1}$, Zhiwen $\mathrm{Ma}^{1}$, Janna Martinek ${ }^{1}$, Craig Turchi ${ }^{1}$ and Jeffrey G. Weissman ${ }^{2}$

1 National Renewable Energy Laboratory

2 Precision Combustion, Inc.

\section{Suggested Citation}

Gifford, Jeffrey, Patrick Davenport, Zhiwen Ma, Janna Martinek, Craig Turchi and Jeffrey G. Weissman. 2019. Analysis of Planar-Cavity Receiver Reactor for Solar Thermochemical Dry-Reforming: Preprint. Golden, CO: National Renewable Energy Laboratory. NREL/CP-5500-73726. https://www.nrel.gov/docs/fy19osti/73726.pdf.

NREL is a national laboratory of the U.S. Department of Energy Office of Energy Efficiency \& Renewable Energy Operated by the Alliance for Sustainable Energy, LLC

This report is available at no cost from the National Renewable Energy Laboratory (NREL) at www.nrel.gov/publications.

Contract No. DE-AC36-08GO28308
Conference Paper NREL/CP-5500-73726 August 2019

National Renewable Energy Laboratory 15013 Denver West Parkway Golden, CO 80401 303-275-3000 • www.nrel.gov 


\section{NOTICE}

This work was authored by the National Renewable Energy Laboratory, operated by Alliance for Sustainable Energy, LLC, for the U.S. Department of Energy (DOE) under Contract No. DE-AC36-08GO28308. The authors gratefully acknowledge funding provided by the Small Business Innovation Research (SBIR) program Phase II. The views expressed herein do not necessarily represent the views of the DOE or the U.S. Government. The U.S. Government retains and the publisher, by accepting the article for publication, acknowledges that the U.S. Government retains a nonexclusive, paid-up, irrevocable, worldwide license to publish or reproduce the published form of this work, or allow others to do so, for U.S. Government purposes.

This report is available at no cost from the National Renewable Energy Laboratory (NREL) at www.nrel.gov/publications.

U.S. Department of Energy (DOE) reports produced after 1991 and a growing number of pre-1991 documents are available free via www.OSTI.gov.

Cover Photos by Dennis Schroeder: (clockwise, left to right) NREL 51934, NREL 45897, NREL 42160, NREL 45891, NREL 48097, NREL 46526.

NREL prints on paper that contains recycled content. 


\section{ANALYSIS OF PLANAR-CAVITY RECEIVER REACTOR FOR SOLAR THERMOCHEMICAL DRY-REFORMING}

\author{
Jeffrey Gifford ${ }^{1}$, Patrick Davenport, Zhiwen \\ Ma, Janna Martinek, Craig Turchi \\ National Renewable Energy Laboratory (NREL) \\ Golden, CO
}

\section{ABSTRACT}

Concentrating solar thermal (CST) systems can be leveraged to provide not only heat for power generation, but also for energy storage and thermochemical fuel production. Such solar thermochemical processes have been studied conceptually, from solar thermochemical hydrogen production (STCH) and thermochemical energy storage (TCES), to gasification, reforming, and fuel upgrading by various means. The solar receiver and reactor are critical components in the conversion of solar energy into chemical energy in the form of "solar fuels". For effective conversion of solar energy within a coupled solar receiver-reactor, extremely high temperatures are required, thereby demanding a high solar concentration ratio (CR) for efficient operation. This creates a design challenge for the receiver-reactor as many thermochemical processes involve gas or gas-solid systems that are limited by low heat transfer coefficients. A unique receiver design is proposed that has the potential to incorporate various high-temperature thermochemical processes such as TCES-assisted power generation, methane reforming, or STCH processes. Modeling this receiver and its potential applications requires a full threedimensional model that accurately captures the interconnected effects of receiver geometry, spatial solar irradiance, complex radiation, reaction kinetics, fluid dynamics, and heat transfer. In this paper we analyze a CST system integrated with this unique planar-cavity receiver-reactor design using the developed model. The model presented in this paper showed where improved thermal management was needed to achieve suitable receiver performance when a dry-methane reforming process is implemented.

Keywords: Solar reactor; Solar receiver; Solar fuels; Solar thermochemical; Concentrated solar power; Solar hydrogen; Syngas; Methane reforming.

\section{NOMENCLATURE}

Symbols:

$\begin{array}{ll}\mathrm{a}-\mathrm{h} & =\text { Shomate coefficients } \\ \mathrm{A} & =\text { Area }\left[\mathrm{m}^{2}\right] \\ \mathrm{C} & =\text { Concentration }\left[\mathrm{mol} / \mathrm{m}^{3}\right] \\ \mathrm{D}_{\mathrm{i}, \mathrm{m}} & =\text { Mass diffusion coefficient } \\ \mathrm{D}_{\mathrm{T}, \mathrm{I}} & =\text { Thermal diffusion coefficient } \\ \mathrm{E}_{\mathrm{a}} & =\text { Activation energy for reaction rate } \\ & \text { constant }[\mathrm{J} / \mathrm{mol}] \\ \mathrm{F} & =\text { Catalyst loading factor [unitless] } \\ \overrightarrow{\mathrm{F}} & =\text { Body force vector }\left[\mathrm{kg} / \mathrm{m}^{2}-\mathrm{s}^{2}\right] \\ \mathrm{h} & =\text { Heat transfer coefficient }\left[\mathrm{W} / \mathrm{m}^{2}-\mathrm{K}\right] \\ \mathrm{H} & =\text { Enthalpy of mixture }[\mathrm{J} / \mathrm{mol}]\end{array}$

\author{
Jeffrey G. Weissman \\ Precision Combustion, Inc. \\ North Haven, CT
}

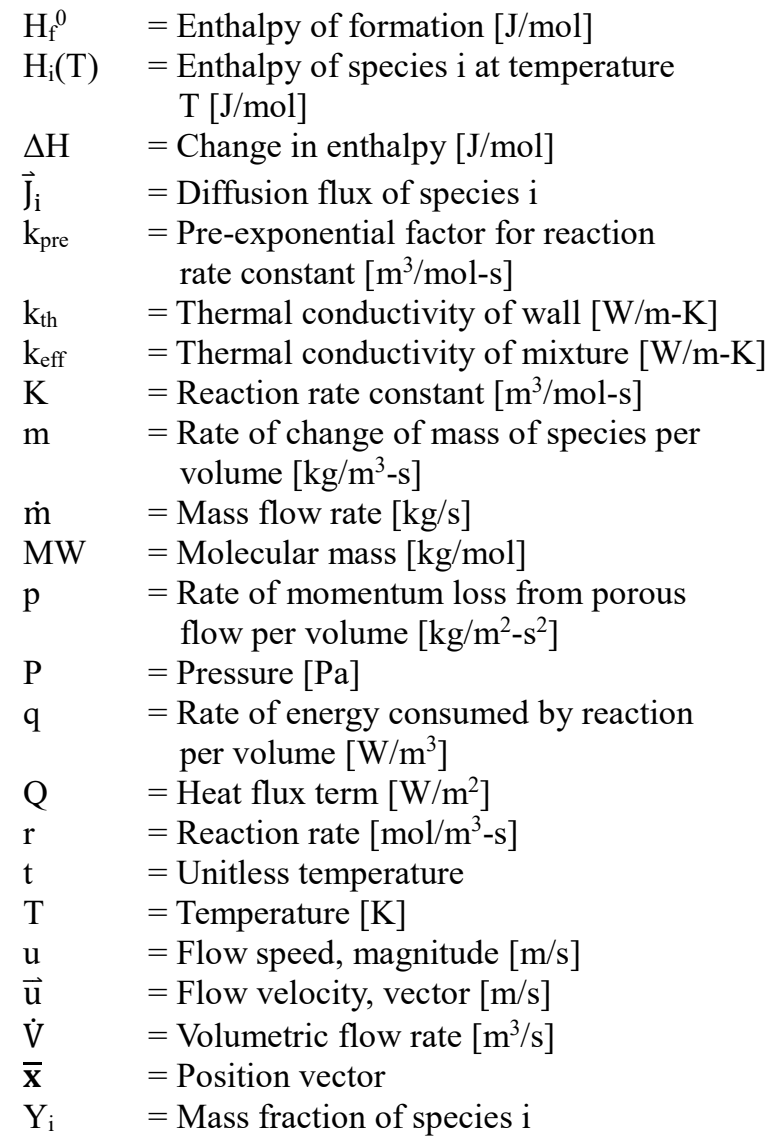

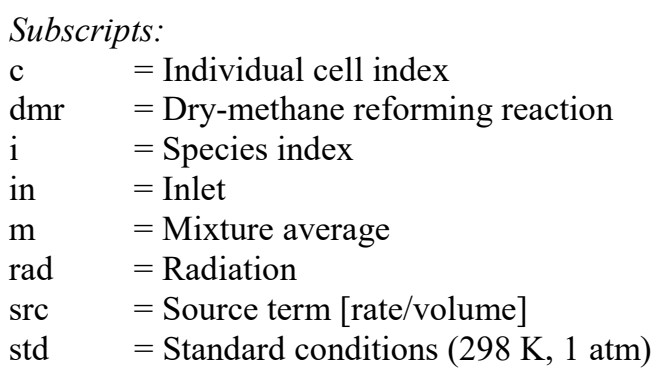

${ }^{1}$ Contact author: Jeffrey.Gifford@nrel.gov 


$$
\begin{array}{ll}
\mathrm{t} & =\text { Total } \\
\mathrm{u}, \mathrm{v}, \mathrm{w} & =\text { Cartesian coordinates } \mathrm{x}, \mathrm{y}, \mathrm{z}
\end{array}
$$

\section{INTRODUCTION}

Research in "solar fuels", typically defined as fuels synthesized using solar energy, is of growing global interest given their potential role within a future energy mix. Solar fuels store solar energy through chemical bonds in a variety of different ways [1-6]. Solar fuels specifically are able to be stored, transported, and used in industrial processes, the transportation sector, and heat and power generation applications, similarly to how traditional fuels are used today [5]. This greatly expands the reach of solar energy beyond solely for electricity generation. Figure 1 demonstrates how solar fuels can play a prominent role in many sectors, specifically through the use of concentrated solar thermal (CST) systems.

CST systems are well-studied, especially for electricity generation which are typically referred to as concentrated solar power (CSP) plants in this function [7]. Furthermore, the cost of a CSP plant is expected to decrease by $61 \%$ from 2018 and 2021 [8]. This makes CST plants more financially attainable in general, therefore, making solar fuels more viable.

As shown in Figure 1, two prominent solar fuels are hydrogen $\left(\mathrm{H}_{2}\right)$ and syngas $\left(\mathrm{H}_{2}+\mathrm{CO}\right)$. Hydrogen is a promising energy carrier for a future "hydrogen economy". While syngas is currently a key feedstock to create different hydrocarbon fuels that can be used in our current infrastructure, i.e. diesel from syngas through the Fischer-Tropsch process [9]. Various commercial processes and plants to convert syngas to different desired products are well-established [10-12].

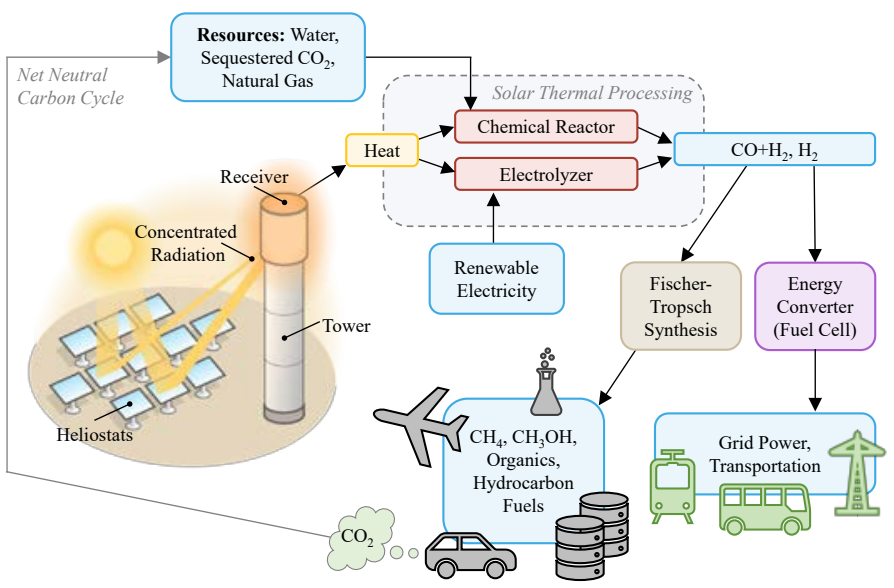

FIGURE 1: Broad potential uses for solar thermal energy through solar fuel production.

There are two primary methods for producing hydrogen and syngas through methane reforming. The two pathways are steam- or dry-methane reforming, the latter is also known as $\mathrm{CO}_{2}$-methane reforming, described by $\mathrm{Eq}$ (1) and respectively.

$$
\begin{gathered}
\mathrm{CH}_{4}+\mathrm{H}_{2} \mathrm{O} \leftrightarrow 3 \mathrm{H}_{2}+\mathrm{CO} \\
\mathrm{CH}_{4}+\mathrm{CO}_{2} \leftrightarrow 2 \mathrm{H}_{2}+2 \mathrm{CO}
\end{gathered}
$$

Steam-methane reforming produces a more hydrogen-rich fuel mixture, but dry-reforming can use sequestered $\mathrm{CO}_{2}$, a potential future feedstock that increases the carbon-negativity of the process. Both reactions are highly endothermic. In the most prevalent commercial hydrogen and syngas production process, steam-methane reforming, the heat needed is provided by burning up to $20 \%$ of the natural gas feedstock [13]. However, it has been well-documented that CST plants are able to effectively and efficiently drive these endothermic reaction $[5,14]$. Therefore, using CST decreases both feedstock consumption and carbon emissions.

Key components of these plants are the solar receiver and reactor. The receiver and reactor can either be coupled or decoupled. When decoupled, the sole role of the receiver is to absorb the solar energy as thermal energy which is then transferred to the reactor elsewhere through heat exchangers. Coupled receiver-reactors contain the catalyst in the same housing where the solar energy is received. Coupled receiverreactors allow for the solar energy to be directly converted to chemical energy instead of thermal energy first [5]. This reduces an energy transfer step, theoretically increasing efficiency of the coupled compared to the decoupled design.

Various solar receiver-reactor designs and models have been proposed [15-17]. While Corgnale et al. used a Helium-heated bayonet reactor, the use of CFD software with energy and species source terms to link the chemical kinetics with the thermodynamics and fluid dynamics was close to what this present study aimed to achieve [18].

This paper presents a more complex model for a novel solar receiver-reactor design. The model is a full-size 3D geometry that has a detailed, spatially-dependent solar heat flux profile mapped onto its exterior walls that is specific to the geometry of this design. This accurately captures the non-uniformity of the incoming solar flux at CST plants. The model incorporates energy and species source terms similar to Corgnale et al., but it also includes momentum source terms to account for porous flow through the imbedded catalyst. A complex but more computationally expensive radiation model is used to capture receiver-to-receiver radiation and greenhouse gas adsorption; the water and carbon-dioxide present in the feedstock are highly absorptive to radiation. A surrounding ambient air domain was also included to accurately capture the effects of natural convection that would occur in the real world. Combined, the model is capable of capturing all the important physics that occur in a coupled solar receiver-reactor.

\section{MODEL DEVELOPMENT}

In this section, the methodology used to construct the model will be described in detail. The model was developed from a technical design to a CFD model with thermochemical mechanisms accounted for through the use of a custom userdefined function (UDF).

\subsection{Model Setup}

The focus of this study was on a single receiver placed on top of the receiving tower of the heliostat field; the receiver was then halved down the line of symmetry to decrease 
computational load. The geometry for this receiver cavity was initially designed in SolidWorks and imported to ANSYS SpaceClaim for final edits and design changes. The entire receiver array was comprised of 25 full, individual receiver cavities (50 halves) that were assembled into an arc; hence, the internal and external planes of symmetry are not perfectly parallel but one degree off.

This specific receiver geometry was chosen because it has been previously studied and shown to have high thermal efficiencies with low reradiation losses [19]. Design changes in this specific study were confined to the interior of the receiver. The changes were comprised of decreasing the width of the inlet channel to increase inlet velocity and designing a curved tip modelled after an impeller turbine to eliminate stagnant flow near the tip to increase cooling. The final geometry can be seen in Figure 2.

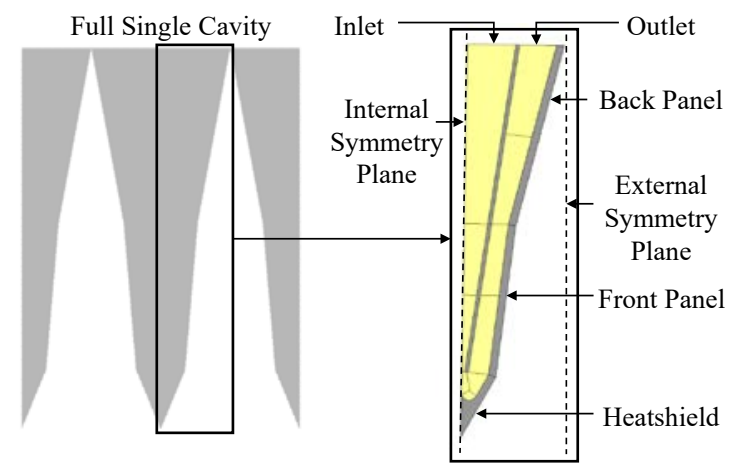

FIGURE 2: A 2D representation of the geometry used in the model. Important planes, faces, and 3D cell zones are labeled. Gray denotes solid walls, yellow denotes gaseous mixture regions.

\subsection{Fluent Case Description}

The CAD drawing was loaded into ANSYS Workbench where desired cell zones and a quality mesh were defined and created using the ANSYS Meshing tool. The mesh used sizing bias near boundary walls and contained 662,178 elements. The mesh was loaded into ANSYS Fluent and a case file was written to save parameters and data. The description of these parameters will be the focus of this sub-section.

One defining factor of this CFD model is the application of a detailed, spatially-dependent heat flux profile on to the surface of the cavity. In previous work by the authors, NREL's SolTrace [20] and SolarPILOT [21] software were used to establish a solar field layout for use with a novel planar-cavity receiver to drive thermochemical processes [22]. The solar field was then used in a 50-million ray SolTrace computation to determine a representative flux profile at a design point; the computation took 8 hours when using 12 cores on a workstation with two Xeon ${ }^{\circledR}$ CPU E5-2440 (2.4. GHz) processors and 192 GB RAM memory. Figure 3 shows the results of this study. The average absorbed solar flux distribution for the seven cavities centered around due North $\left(0^{\circ}\right)$ were used for the analysis presented in this paper.

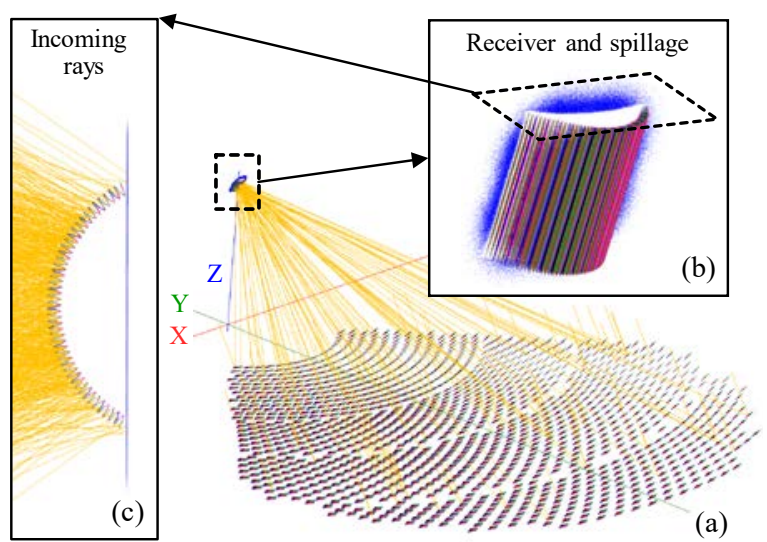

FIGURE 3: Monte Carlo ray tracing evaluation showing (a) the complete receiver and heliostat field with exemplary rays, (b) the detailed receiver cavity elements and spillage plate, and (c) the receiver top view.

Using the SolTrace output data and post-processing in Python and Excel, the heat flux profiles for each of the three receiving planes were constructed. Initially, these profiles were entered as flux values along 2D walls to verify correct translation from SolTrace to Fluent. This step was validated based on the results shown below in Figure 4. In the final implementation, the heat flux values were divided by $1 \mathrm{~mm}$ then mapped as volumetric heat generation profiles on the receiving walls that were defined to also be $1 \mathrm{~mm}$ thick. This resulted in the same solar energy input both spatially and quantitatively.
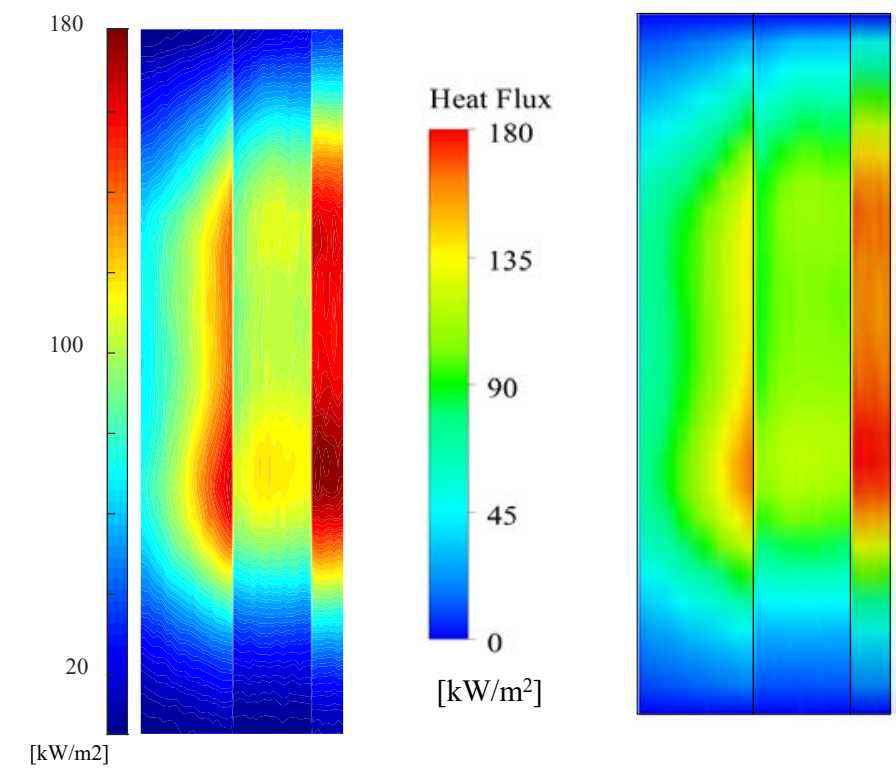

(a)

(b)

FIGURE 4: The heat flux profile mapping technique was validated by the contours above outputted by (a) SolTrace and (b) Fluent. From right to left: the back panel, the front panel, and the heat shield walls. The aspect ratio of both figures has been manipulated for visual clarity. 
In addition to the spatial-dependent solar flux, the boundary conditions for the outer walls were also subject to natural convective and radiative heat transfer conditions. Natural convection was accounted for by creating an ambient air domain surrounding the cavity containing variable-density air based on the ideal gas equation of state. The walls of this ambient air domain were defined as pressure-outlets to allow for air to flow in or out as needed by the solver. To drive buoyancy for natural convection, gravity was included in the solution calculations. Furthermore, to account for the receiver's $15^{\circ}$ forward tilt about the $\mathrm{x}$-axis, the $\mathrm{y}$ - and $\mathrm{z}$-components of the gravity vector were calculated to be $-9.4757 \mathrm{~m} / \mathrm{s}^{2}$ and $-2.5390 \mathrm{~m} / \mathrm{s}^{2}$, respectively.

Since radiative heat transfer between exterior walls of adjacent receivers was a key design feature of this unique receiver geometry, a comprehensive radiation model was needed.

The built-in Surface-to-Surface (S2S) radiation model was the first tested radiation model. S2S is a view factor-based model and ignores effects of fluid between solid walls. Because S2S can handle symmetry boundaries, it can capture the radiative heat transfer between adjacent receivers.

However, this radiative heat transfer model was not accurate enough due to the presence of significant quantities of water vapor and carbon dioxide in the fluid mixture flowing inside the receiver. Water and carbon dioxide are strong greenhouse gases that have absorption coefficients of 0.54 and 0.43 , respectively. Therefore, the built-in Discrete Ordinates (DO) radiation model was employed. The DO model is capable of accounting for the absorption and scattering of gases and automatically incorporates radiative heat transfer between the exterior and interior walls. Consequently, this radiation model lead to a substantial increase in the computational load. Compared to the $\mathrm{S} 2 \mathrm{~S}$ model, this yielded more representative thermal distributions within the internal fluid flow by allowing for thermal absorption as well as heat transfer to the interior walls.

This creates a Neumann boundary condition for the CFD solver along the domain boundaries for the back panel, front panel, and heat shield walls: $\Gamma_{\mathrm{BP}}, \Gamma_{\mathrm{FP}}$, and $\Gamma_{\mathrm{HS}}$, respectively. Mathematically, this can be represented by Eq (3).

$$
\mathrm{Q}_{\mathrm{t}}(\overline{\mathbf{x}})=-\mathrm{k}_{\mathrm{th}}\left(\frac{\partial \mathrm{T}}{\partial \mathrm{n}}\right), \forall \overline{\mathbf{x}} \in \Gamma_{\mathrm{BP}}, \Gamma_{\mathrm{FP}}, \Gamma_{\mathrm{HS}}
$$

Other relevant material properties for the walls of the receiver, such as density, specific heat, and thermal conductivity were defined as $8900.0 \mathrm{~kg} / \mathrm{m}^{3}, 460.6 \mathrm{~J} / \mathrm{kg}-\mathrm{K}$, and $35.0 \mathrm{~W} / \mathrm{m}-\mathrm{K}$, respectively.

The inlet boundary condition was set up as a Dirichlet boundary condition; the boundary condition, therefore, needs to specify values for various fluid flow properties. The Fluent model required inlet temperature, pressure, mass flow rate, and mass fraction of all species to fully define the Dirichlet inlet boundary condition. Using the given inlet condition presented in Table 1, the inlet speed was calculated using Eq (4).
TABLE 1: Thermodynamic properties of the inlet mixture.

\begin{tabular}{|l|c|}
\hline Property & Value \\
\hline Temperature [K] & 886.78 \\
\hline Pressure [bar] & 1.05 \\
\hline $\begin{array}{l}\text { Std. Volumetric Flow Rate (for half of a single } \\
\text { receiver) }\left[\mathrm{m}^{3} / \mathrm{s}\right]\end{array}$ & 133.44 \\
\hline Area $\left[\mathrm{m}^{2}\right]$ & 0.1614 \\
$\qquad \mathrm{u}_{\text {in }}=\frac{\left(\dot{\mathrm{V}}_{\text {in,std }}\right)\left(\frac{\mathrm{T}_{\text {in }}}{\mathrm{T}_{\text {std }}}\right)\left(\frac{\mathrm{P}_{\text {std }}}{\mathrm{P}_{\text {in }}}\right)}{\mathrm{A}_{\text {in }}}$ \\
$\qquad \mathrm{Y}_{\mathrm{in,i}}=\frac{\dot{\mathrm{m}}_{\mathrm{in}, \mathrm{i}}}{\sum \dot{\mathrm{m}}_{\text {in, } \mathrm{i}}}$
\end{tabular}

The species mass fractions were calculated using Eq (5) and the data found in the center column in Table 2. The calculated mass fractions of each species at the inlet can be found in the right column in Table 2. This concludes the inlet boundary conditions for this case.

TABLE 2: Given mass flow rates for each species for a full receiver array and their computed mass fractions in order to define inlet composition.

\begin{tabular}{|l|c|c|}
\hline Species & $\begin{array}{c}\text { Inlet Mass Flow } \\
\text { Rate }[\mathbf{k g} / \mathbf{s}]\end{array}$ & $\begin{array}{c}\text { Inlet Mass } \\
\text { Fraction }\end{array}$ \\
\hline Hydrogen $\left(\mathrm{H}_{2}\right)$ & 0.010 & 0.006 \\
\hline Water $\left(\mathrm{H}_{2} \mathrm{O}\right)$ & 0.450 & 0.261 \\
\hline Carbon Monoxide $(\mathrm{CO})$ & 0.102 & 0.059 \\
\hline Carbon Dioxide $\left(\mathrm{CO}_{2}\right)$ & 0.571 & 0.330 \\
\hline Methane $\left(\mathrm{CH}_{4}\right)$ & 0.559 & 0.323 \\
\hline Ethane $\left(\mathrm{C}_{2} \mathrm{H}_{6}\right)$ & 0.021 & 0.013 \\
\hline Propane $\left(\mathrm{C}_{3} \mathrm{H}_{8}\right)$ & 0.004 & 0.003 \\
\hline Nitrogen $\left(\mathrm{N}_{2}\right)$ & 0.010 & 0.005 \\
\hline
\end{tabular}

The next phase of development of the model focused on the $3 \mathrm{D}$ cell zones within the receiver where the mixture is present. In order to model the thermochemical mechanisms occurring within these cell zones, the Fluent models "Energy" and "Species Transport" were activated in addition to the already activated "Radiation" model. This allowed for energy and species source terms to be added to all cell zones where the chemical reactions would be occurring. The equations and the respective derivations for these source terms are detailed in Section 2.3, Mathematical Description.

Porous media inputs were required for any cell zone that contained the catalyst. The momentum source term was also correspondingly added; details of this source term can be found in the following section with the other source term descriptions. No catalyst was placed in the inlet channel to allow for highspeed unresisted flow that also saves reactants for the endothermic reaction occurring in the hotter tip and outlet channels. In future work, more detailed catalyst design parameters would be modelled.

\subsection{Mathematical Description}

This section will describe the development and purpose of the UDF created for this model. The UDF interacts primarily 
with Fluent through source terms. Source terms are rates of production or consumption in a cell of energy, species, or momentum normalized per unit of volume. The UDF can also contain initialization equations as well as set up desired userdefined variables, UDMs (user-defined memory), that are tied to each individual cell (i.e. the rate constant for dry-methane reforming within each cell). The UDF has access to flow property values from Fluent for calculation purposes.

Specifically, the UDF was used to model the thermochemical effects of the dry-methane reforming (DMR) reaction. The UDF defined species mass source terms for methane, carbon dioxide, carbon monoxide, and hydrogen, and an energy source term for the energy consumed by the endothermic reaction. Also, the UDF specified momentum sinks caused by the porous catalyst.

\subsubsection{DMR Reaction}

The DMR reaction was the reaction modelled within the reactor. The chemical equation for this reaction is described by $\mathrm{Eq}(2)$.

The reaction rate constant was calculated using a standard Arrhenius equation, Eq (6), to accurately account for the significant changes in temperature at various points throughout the flow field, as seen in Figure 5(a) in Section 3.1, Flow Field Results. The catalyst loading factor $F$ is directly proportional to the catalyst loading. $F$ was defined as unity throughout the domain for this model but included for application in future studies into varying catalyst loadings.

$$
K=F k_{\text {pre }} e^{-\frac{E_{a}}{R T}}
$$

Using the reaction rate constant, the reaction was able to be calculated using a second-order reaction rate equation, as seen in Eq (7). The molar concentrations of all species were tracked using UDMs and calculated for each cell, as seen in Eq (8). Mass fraction for a given species in a cell and total density of that cell were properties extracted from Fluent.

$$
\begin{gathered}
\mathrm{r}_{\mathrm{dmr}}=\mathrm{K}\left[\mathrm{CH}_{4}\right]\left[\mathrm{CO}_{2}\right] \\
{[\mathrm{i}]=\frac{\mathrm{Y}_{\mathrm{i}, \mathrm{c}} \rho_{\mathrm{c}}}{\mathrm{MW}_{\mathrm{i}}}}
\end{gathered}
$$

The DMR reaction rate was used in the calculation of energy and species source terms. For the energy source term, the enthalpy of reaction, Eq (10), was required and dependent on temperature. Shomate's polynomial coefficients were used to calculate enthalpies in the UDF for each species at each cell's specific temperature, as seen in $\mathrm{Eq}(9)$.

$$
\begin{gathered}
\mathrm{H}_{\mathrm{i}}\left(\mathrm{T}_{\mathrm{c}}\right)=\mathrm{H}_{\mathrm{f}, \mathrm{i}}^{0}+\left(\mathrm{h}_{\mathrm{T}, \mathrm{i}}-\mathrm{h}_{298.15, \mathrm{i}}\right)= \\
\mathrm{H}_{\mathrm{f}, \mathrm{i}}^{0}+\left[\mathrm{a}_{\mathrm{i}} \mathrm{t}+\left(\frac{\mathrm{b}_{\mathrm{i}}}{2}\right) \mathrm{t}^{2}+\left(\frac{\mathrm{c}_{\mathrm{i}}}{3}\right) \mathrm{t}^{3}+\left(\frac{\mathrm{d}_{\mathrm{i}}}{4}\right) \mathrm{t}^{4}-\right. \\
\left.\frac{\mathrm{e}_{\mathrm{i}}}{\mathrm{t}}+\mathrm{f}_{\mathrm{i}}-\mathrm{h}_{\mathrm{i}}\right]
\end{gathered}
$$

Where $\mathrm{t}=\mathrm{T}_{\mathrm{c}} / 1000 \mathrm{~K}$.

$$
\begin{gathered}
\Delta \mathrm{H}_{\mathrm{dmr}}=\left[2 \mathrm{H}_{\mathrm{H}_{2}}\left(\mathrm{~T}_{\mathrm{c}}\right)+2 \mathrm{H}_{\mathrm{CO}}\left(\mathrm{T}_{\mathrm{c}}\right)\right]- \\
{\left[\mathrm{H}_{\mathrm{CH}_{4}}\left(\mathrm{~T}_{\mathrm{c}}\right)+\mathrm{H}_{\mathrm{CO}_{2}}\left(\mathrm{~T}_{\mathrm{c}}\right)\right]}
\end{gathered}
$$

The energy source term was calculated as shown below in Eq (11). Since a positive change in enthalpy of reaction signifies an endothermic reaction, the energy source term needs to be negated to act as an energy sink.

$$
\mathrm{q}_{\mathrm{src}}=\mathrm{r}_{\mathrm{dmr}}\left(-\Delta \mathrm{H}_{\mathrm{dmr}}\right)
$$

The energy source term was added to the global energy equation solved by Fluent described by Eq (12).

$$
\begin{gathered}
\nabla \cdot\left(\overrightarrow{\mathrm{u}}\left(\rho_{\mathrm{m}} \mathrm{E}+\mathrm{P}\right)\right)=\nabla \cdot\left(\mathrm{k}_{\mathrm{eff}} \nabla \mathrm{T}-\sum_{\mathrm{i}} \mathrm{h}_{\mathrm{i}} \overrightarrow{\mathrm{J}}_{\mathrm{i}}+\right. \\
\left.\left(\overline{\overline{\mathrm{\tau}}}_{\text {eff }} \cdot \overrightarrow{\mathrm{u}}\right)\right)+\mathrm{q}_{\mathrm{rad}}+\mathrm{q}_{\mathrm{src}}
\end{gathered}
$$

Where $q_{\text {rad }}$ is any radiative energy source term computed by the radiation model and $E$ is defined by Eq (13).

$$
\mathrm{E}=\mathrm{h}_{\mathrm{m}}-\frac{\mathrm{P}}{\rho_{\mathrm{m}}}+\frac{\mathrm{u}^{2}}{2}
$$

The species involved in this reaction, methane, carbon dioxide, carbon monoxide, and hydrogen were each given species source terms, defined by Eq (14). The source terms were based on the reaction rate and their respective stoichiometric coefficients according to Eq (2). Products and reactants were given positive and negative coefficients, respectively.

$$
\mathrm{m}_{\mathrm{src}, \mathrm{i}}= \pm \gamma_{\mathrm{i}} \mathrm{r}_{\mathrm{dmr}} \mathrm{MW}_{\mathrm{i}}
$$

The DMR species are the sole species involved that have source terms. The species mass source term was added to global species conservation equation for species $i$ solved by Fluent described by Eq (15).

$$
\begin{gathered}
\nabla\left(\rho \vec{u} Y_{i}\right)= \\
-\nabla \cdot\left(\rho D_{i, m} \nabla Y_{i}-D_{T, i} \frac{\nabla T}{T}\right)+m_{s r c, i}
\end{gathered}
$$

Since mass is conserved in the domain, there is no need to explicitly define cell zone mass and momentum source terms with regard to the DMR reaction.

\subsubsection{Porous Media}

An additional function of the UDF in this model was to provide momentum source terms due to the presence of a porous catalyst medium in particular cell zones. While Fluent can model porous media, there are no momentum losses associated with the porous media. Therefore, the UDF for this model accounts for momentum losses through a momentum sink term defined by Darcy's law, Eq (16). While Fluent used the inverse of permeability, Darcy's law requires permeability. Similar to the energy source term, the negative momentum source term signifies a momentum sink.

$$
\mathrm{p}_{\mathrm{src}, \mathrm{u} / \mathrm{v} / \mathrm{w}}=-\frac{\mu}{\kappa} \mathrm{v}_{\mathrm{u} / \mathrm{v} / \mathrm{w}}
$$


These momentum source terms were added to the global momentum conservation equation solved by Fluent defined by Eq (17).

$$
\nabla \cdot(\rho \vec{u} \vec{u})=-\nabla P+\nabla \cdot \overline{\bar{\tau}}+\rho \vec{g}+\vec{F}+\vec{p}_{s r c}
$$

This concludes the full methodology for the creation of this dry-methane reforming solar cavity receiver-reactor model.

\section{RESULTS AND DISCUSSION}

\subsection{Flow Field Results}

The temperature and velocity distributions together, shown in Figure 5(a) and (b), respectively, show successful application of an impinging jet cooling the tip of the receiver. The fluid is accelerated through the inlet channel and then successfully makes full contact along the tip wall as it turns outward towards the outlet channel. The effect of this velocity profile is evident in the temperature distribution with the hotter fluid regions being located further down the outlet channel; a distinct, thin, cool layer of fluid is also visible long the curved tip. Quantitatively, out of the three exterior walls, the heat shield has the lowest average temperature of $1272 \mathrm{~K}$; this is between $50-60 \mathrm{~K}$ less than the average temperature of the other exterior walls.

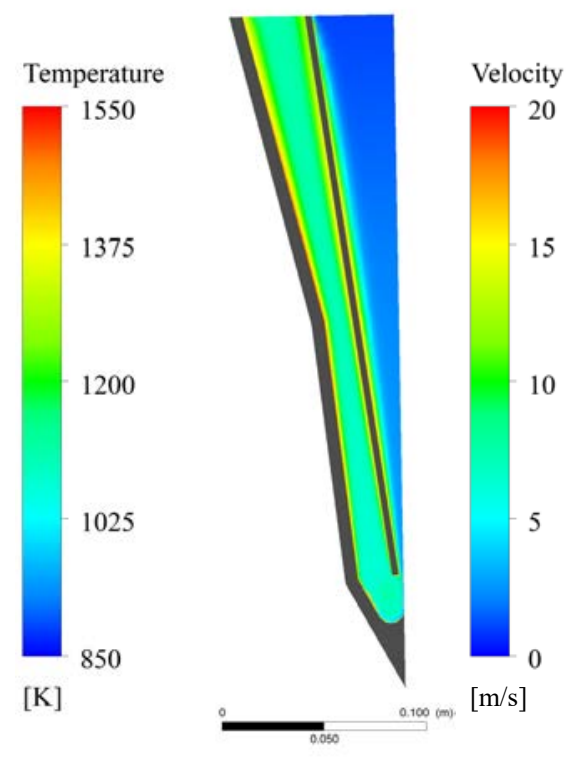

(a)

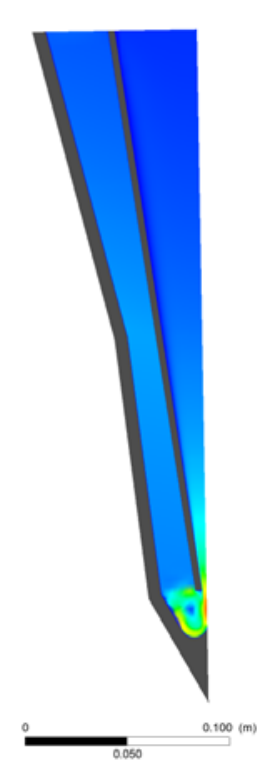

(b)
FIGURE 5: Fluid (a) temperature and (b) absolute velocity contours on a plane centered in the fluid domain.

Also, the temperature distribution shows that the central inlet channel design indeed allows for preheating of the inlet mixture. The inlet mixture temperature increases from $888 \mathrm{~K}$ at the beginning of the inlet channel to $1015 \mathrm{~K}$ at the end of the inlet channel. This reduces the heat input requirement upstream of the reactor.

The temperature

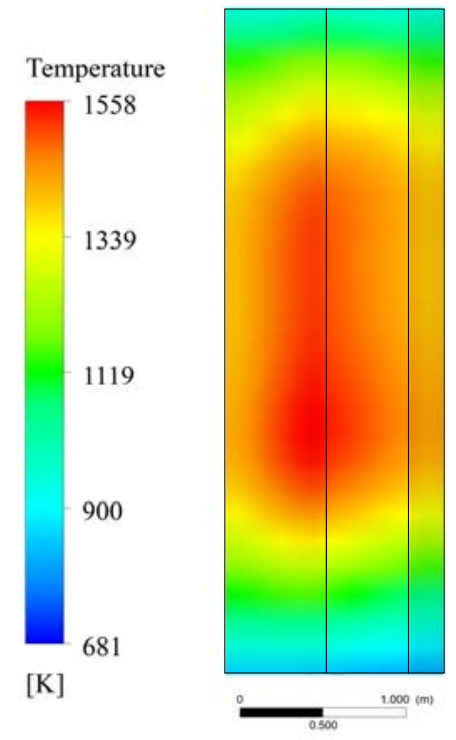

FIGURE 6: Temperature distribution along the exterior walls of the receiver. From left to right: the back panel, front panel, and heat shield walls. Aspect ratio has been manipulated for visualization purposes. distribution in the outlet channel of the receiver, shown in Figure 5(a), showed a lack of mixing between the fluid close to and the fluid far from the receiver walls. This prevented the dry-reforming reaction from occurring in the bulk of the fluid flow due to the minimum temperature, or threshold temperature, for the reaction to occur, which was initially defined as $1113 \mathrm{~K}$. The lack of thermal distribution within the fluid was partially attributed to the low magnitude velocity, shown in Figure 5(b). Low velocity magnitudes combined with a relatively lowdensity mixture due to the high temperatures and low pressures contribute to a low Reynolds number. Low Reynolds numbers yield laminar flows which have much lower heat transfer coefficients compared to turbulent flows.

The temperature distribution on the exterior walls, shown in Figure 6, was evaluated to see if there was insufficient solar flux being applied to the exterior. Temperatures in excess of the threshold temperature were found across the majority of the area of these walls; the temperature change between the exterior- and interiorside of these solid walls was negligible. The spatial-average temperature on the exterior walls was $1324 \mathrm{~K}$, higher than threshold temperature. A lower average temperature would also be achieved by increasing heat transfer to the interior fluid. To calculate the percentage of the exterior wall area that reached the threshold temperature for the DMR reaction, a Boolean UDM was created based on the surface temperature of each face on the exterior walls (i.e. 1 for above the threshold temperature, 0 for below threshold temperature). A surface integral of this userdefined memory value calculated that more than $80 \%$ of the total area of the exterior walls was at or above the threshold temperature.

The temperature distribution in Figure 6 differs from the incident solar radiation distribution, shown in Figure 4(b), due to the radiation effects, through differing view factors summarized in Table 3, and thermal management effects, through the impinging jet and preheating, of the receiver. This explains why the back panel was the location of the highest point temperature, $1552 \mathrm{~K}$. 
TABLE 3: Total view factors for exterior walls of the receiver to the adjacent receiver walls.

\begin{tabular}{|l|c|c|c|}
\hline & $\begin{array}{c}\text { To Heat } \\
\text { Shield }\end{array}$ & $\begin{array}{c}\text { To Front } \\
\text { Panel }\end{array}$ & $\begin{array}{c}\text { To Back } \\
\text { Panel }\end{array}$ \\
\hline $\begin{array}{l}\text { From Heat } \\
\text { Shield }\end{array}$ & 0.1588 & 0.1715 & 0.0024 \\
\hline $\begin{array}{l}\text { From Front } \\
\text { Panel }\end{array}$ & 0.0777 & 0.5066 & 0.1844 \\
\hline $\begin{array}{l}\text { From Back } \\
\text { Panel }\end{array}$ & 0.0008 & 0.1506 & 0.7551 \\
\hline
\end{tabular}

Furthermore, to ensure that convective heat transfer was taking place in the ambient air domain, the velocity field from part of this domain was examined. Natural convection is driven by buoyancy due to small changes in density between hot and cold air. Therefore, the velocity field should be accelerated upward along the hot walls of the cavity and stagnant elsewhere. Figure 7 shows this was indeed happening in the air between the receivers. The velocity profile increased along the upward-vertical direction of the face of the cavity, peaking at the top of the cavity before velocity dissipated in the air above the cavity.

\subsection{Preliminary Reaction Results}

A brief analysis of the reaction results was then conducted. Figure 8 shows the areas in which the DMR reaction is activated (i.e. the region of the fluid domain where the fluid has reached the threshold temperature). Similar to the methodology used to calculate the percentage of the exterior walls above the threshold temperature, a Boolean UDM value was created for the fluid domain as well. This UDM was set to 1 or 0 if the temperature of a cell in the fluid domain was above or below, the required temperature, respectively. Therefore, a volume integral over the fluid domain that contains catalyst (i.e. the tip and outlet channel) of this UDM would calculate the total volume where the DMR reaction took place. In doing so, the total volume above the threshold temperature was calculated to be only $0.00798 \mathrm{~m}^{3}$,
FIGURE 7: Ambient air velocity field on the exterior of the receiver. Aspect ratio was manipulated for visualization purposes.

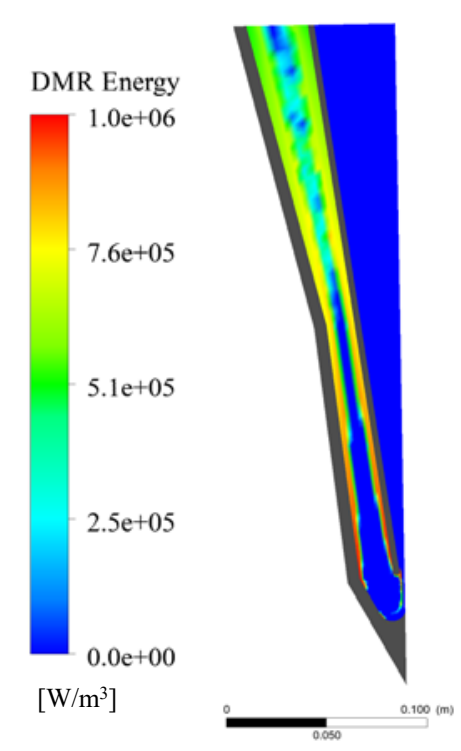

FIGURE 8: Energy source term from the DMR reaction.

compared to the total volume of the same region, 0.02269 $\mathrm{m}^{3}$. This meant only $35.17 \%$ of the fluid domain was being utilized for the DMR reaction.

The total energy consumed and conversion rates were not the focus of this study as limited reaction kinetic knowledge for the selected catalyst was available. The reaction results presented here are meant to emphasize that the total active volume of the reactor is limited by the need for better internal thermal mixing.

\subsection{Higher \\ Temperature Case}

Upon analysis of these results, the inlet temperature was increased to $1173 \mathrm{~K}$ which was deemed achievable through the use of tail-gas burner. The threshold temperature was also decreased to $1073 \mathrm{~K}$.

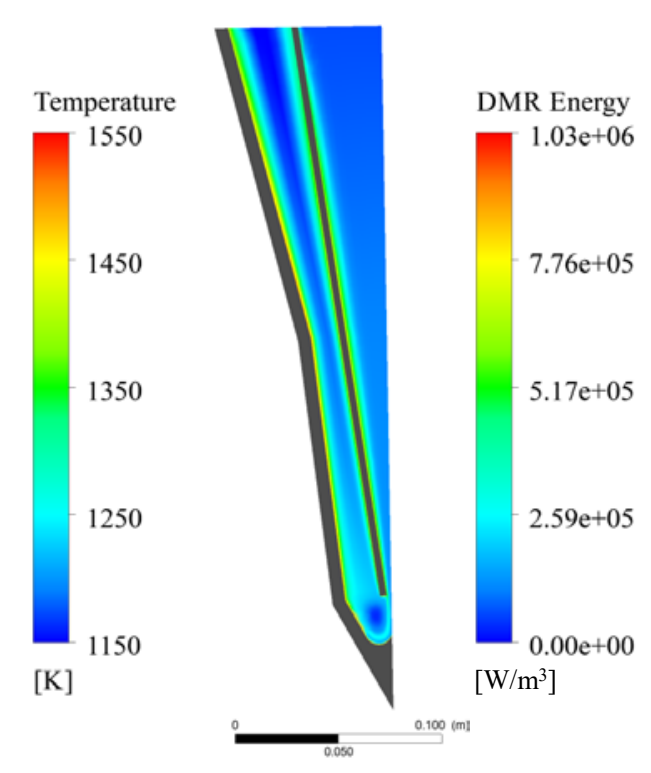

(a)
Inlet ese (n) -

FIGURE 9: (a) Fluid temperature distribution in the center plane. Note the $300 \mathrm{~K}$ increase in the lowest contour limit compared to Figure 5(a) made to highlight the temperature distribution. (b) Energy source term from the DMR reaction.

As expected, the results presented in Figure 9 show a significant increase in temperature and DMR activity over the previous case. The average fluid temperature increased from $1016 \mathrm{~K}$ to $1198 \mathrm{~K}$. The average fluid temperature increase creates a dramatic increase in the volume of the receiver 
participating in the DMR reaction; this is evident when comparing Figure 8 and 9(b). The active volume percentage increases by 2.7 times.

The spatial-average exterior wall temperature increased slightly from $1322 \mathrm{~K}$ to $1391 \mathrm{~K}$. Most interestingly, the back panel changed from the hottest average temperature to the lowest of the three external walls; this is attributed to the higher inlet temperature. This result highlights the design importance of the impinging jet as the only change was the inlet temperature - the view factors were unchanged because the geometry was unchanged - and this led to an increase in the average temperature of the heat shield. The receiver-reactor geometry's ability to preheat the fluid was cut by two-thirds; the average fluid temperature increased by only $4.7 \%$ along the inlet channel, compared to $14.7 \%$ in the original case.

\subsection{Receiver and Model Improvements}

Based on these results, increasing the fluid velocity, adding vortex generators, using smaller flow channels, or installing thermal fins would be valuable changes to the receiver in future studies to increase thermal distribution within the fluid. Vortex generators would increase fluid mixing and thereby improve heat transfer, resulting in a better thermal distribution. Adding smaller flow channels would decrease the physical distance between bulk flow regions and the heated walls. Thermal fins would also be another common solution to increase heat transfer.

One of or a combination of these solutions would improve upon the current thermal management abilities of the receiver. Increasing the volume of the receiver undergoing the highly endothermic reaction without increasing the inlet temperature would be ideal. This would lower the temperature of the exterior walls as more of the solar energy is absorbed by the reaction.

In future studies, the model will incorporate more specific reaction kinetics. Currently, the results demonstrate the model's ability to integrate a solar reforming reaction, but the reaction kinetics need to be better understood through robust experimental tests before the conversion rates predicted by the model are confident.

Lastly, transient cases should be studied as the solar resource is notably variable throughout times of the day and seasons. These changes would be easily implemented into the current model, as it was designed to be customizable for different solar flux profiles.

\section{CONCLUSION}

A full-size, detailed solar receiver-reactor model was developed for integration into a CST system for solar thermochemical processing. A UDF was written to increase the complexity and functionality of ANSYS Fluent's thermo-fluid modelling capabilities through the integration of a preliminary dry-methane reforming reaction. The receiver-reactor's thermal management capabilities were studied in depth. The model showed the crucial tip temperature can be kept cool enough through the use of an impinging jet created by the inlet gases. Those inlet gases were shown to also be preheated through the inner-to-outer flow design. The model leaves room for flexibility in future applications to analyze a diverse range of thermochemical processes and solar applications.

\section{ACKNOWLEDGEMENTS}

This work was authored by the National Renewable Energy Laboratory, operated by Alliance for Sustainable Energy, LLC, for the U.S. Department of Energy (DOE) under Contract No. DE-AC36-08GO28308. The authors gratefully acknowledge funding provided by DE-SC0015855 SBIR Phase II. The views expressed in the article do not necessarily represent the views of the DOE or the U.S. Government. The U.S. Government retains and the publisher, by accepting the article for publication, acknowledges that the U.S. Government retains a nonexclusive, paid-up, irrevocable, worldwide license to publish or reproduce the published form of this work, or allow others to do so, for U.S. Government purposes.

\section{REFERENCES}

[1] Steinfeld, A., 2002, "Solar Hydrogen Production via a Two-Step Water-Splitting Thermochemical Cycle Based on $\mathrm{Zn} / \mathrm{ZnO}$ Redox Reactions," Int. J. Hydrogen Energy, 27(6), pp. 611-619.

[2] Kolb, G. J., Diver, R. B., and Siegel, N., 2007, “CentralStation Solar Hydrogen Power Plant,” J. Sol. Energy Eng., 129(2), p. 179.

[3] Lin, M., and Haussener, S., 2018, "An Integrated Concentrated Solar Fuel Generator Utilizing a Tubular Solid Oxide Electrolysis Cell as Solar Absorber," J. Power Sources, 400(5), pp. 592-604.

[4] Tamme, R., Buck, R., Epstein, M., Fisher, U., and Sugarmen, C., 2001, "Solar Upgrading of Fuels for Generation of Electricity,” J. Sol. Energy Eng., 123(2), p. 160 .

[5] Agrafiotis, C., von Storch, H., Roeb, M., and Sattler, C., 2014, "Solar Thermal Reforming of Methane Feedstocks for Hydrogen and Syngas Production-A Review," Renew. Sustain. Energy Rev., 29, pp. 656-682.

[6] Marxer, D., Furler, P., Scheffe, J., Geerlings, H., Falter, C., Batteiger, V., Sizmann, A., and Steinfeld, A., 2015, "Demonstration of the Entire Production Chain to Renewable Kerosene via Solar Thermochemical Splitting of H $2 \mathrm{O}$ and CO 2," Energy \& Fuels, 29(5), pp. 3241-3250.

[7] Islam, M. T., Huda, N., Abdullah, A. B., and Saidur, R., 2018, "A Comprehensive Review of State-of-the-Art Concentrating Solar Power (CSP) Technologies: Current Status and Research Trends," Renew. Sustain. Energy Rev., 91(4), pp. 987-1018.

[8] International Renewable Energy Agency (IRENA), 2018, Renewable Power Generation Costs in 2018.

[9] Yao, Y., Liu, X., Hildebrandt, D., and Glasser, D., 2011, "Fischer-Tropsch Synthesis Using H2/CO/CO2 Syngas Mixtures over an Iron Catalyst,' Ind. Eng. Chem. Res., 50, pp. 11002-11012.

[10] Hindman, M., 2017, "ExxonMobil Methanol to 
Gasoline," Syngas Technology Conference, Colorado Springs, October.

[11] Radtke, K., "Syngas Technologies at Thyssenkrupp:," 2017 Syngas Technologies Conference.

[12] Lucero, A., Basu, B., Cline, B., Woolcock, P., and Thompson, C., 2017, "Selective Conversion of Syngas to JP-8 Jet Fuel Project Team CTL Process Concept Hybrid Selective FT Synthesis Summary," 2017 Syngas Technologies Conference.

[13] Mueller-Langer, F., Tzimas, E., Kaltschmitt, M., and Peteves, S., 2007, "Techno-Economic Assessment of Hydrogen Production Processes for the Hydrogen Economy for the Short and Medium Term," Int. J. Hydrogen Energy, 32(16), pp. 3797-3810.

[14] Hirsch, D., Epstein, M., and Steinfeld, A., 2001, "The Solar Thermal Decarbonization of Natural Gas," Int. J. Hydrogen Energy, 26(10), pp. 1023-1033.

[15] Bellan, S., Alonso, E., Perez-Rabago, C., GonzalezAguilar, J., and Romero, M., 2013, "Numerical Modeling of Solar Thermochemical Reactor for Kinetic Analysis," Energy Procedia, 49, pp. 735-742.

[16] Bellan, S., Kodama, T., Matsubara, K., Gokon, N., Cho, H. S., and Inoue, K., 2019, "Thermal Performance of a $30 \mathrm{~kW}$ Fluidized Bed Reactor for Solar Gasification: A CFD-DEM Study,” Chem. Eng. J., 360(10), pp. 12871300.

[17] Kopping, S. J., Hoeniges, J., Greenhagen, J., Matejczyk,
Z., and Venstrom, L. J., 2019, "Model of the SolarDriven Reduction of Cobalt Oxide in a Particle Suspension Reactor," Sol. Energy, 177(11), pp. 713723.

[18] Corgnale, C., Shimpalee, S., Gorensek, M. B., Satjaritanun, P., Weidner, J. W., and Summers, W. A., 2017, "Numerical Modeling of a Bayonet Heat Exchanger-Based Reactor for Sulfuric Acid Decomposition in Thermochemical Hydrogen Production Processes," Int. J. Hydrogen Energy, 42(32), pp. 20463-20472.

[19] Ma, Z., and Martinek, J., 2019, "Analysis of Solar Receiver Performance for Chemical-Looping Integration With a Concentrating Solar Thermal System,” J. Sol. Energy Eng., 141(2), p. 021003.

[20] Wendelin, T., Dobos, A., Lewandowski, A., Wendelin, T., and Dobos, A., 2013, "SolTrace: A Ray-Tracing Code for Complex Solar Optical Systems," (10).

[21] Wagner, M. J., and Wendelin, T., 2018, "SolarPILOT: A Power Tower Solar Field Layout and Characterization Tool," Sol. Energy, 171(6), pp. 185-196.

[22] Davenport, P., Martinek, J., and Ma, Z., 2019, “Analysis of Concentrating Solar Thermal System to Support Thermochemical Energy Storage or Solar Fuel Generation Processes," 13th International Conference on Energy Sustainability, pp. 1-10. 